\title{
Application of Glodon BIM 5D technology in Gucun international foreign language school
}

\author{
Zhijie Yuan ${ }^{1, *}, H u a \mathrm{Li}^{2}$, and Feng $\mathrm{Xu}^{1}$ \\ ${ }^{1}$ School of Naval Architecture, Ocean and Civil Engineering, Shanghai Jiao Tong University, 200240 Shanghai, China \\ ${ }^{2}$ Shanghai Baoye group co. LTD, 200941 Shanghai, China
}

\begin{abstract}
Glodon BIM5D technology was used in the project of gucun world foreign language school, which connected the BIM $3 \mathrm{~d}$ model of the project with the construction progress and project cost. The results showed that the project team uses the same model for engineering calculation and valuation. The automatic calculation of the imported model not only improved the accuracy of compiling budget estimates and budgets, but also shortened the time of compiling budget estimates and budgets by $30 \%$ and saved the construction period. Glodon BIM 5D was used to get through the model, cost and schedule information to help optimize the construction organization and strengthen the control of the construction process.
\end{abstract}

\section{Introduction}

\subsection{Foreign Research \& Status}

The concept of BIM was proposed by Professor Eastman ${ }^{[1]}$ from the United States in September 1974. The ability to visualize, coordinate, and optimize BIM technology was demonstrated by the general services administration (GSA) through the application of BIM in projects ${ }^{[2]}$. Based on BIM4D technology, reasonable arrangement of construction sequence and construction resources was realized by Jan Tulke ${ }^{[3]}$. Tamera et al. ${ }^{[4]}$ applied BIM4D and BIM5D technology respectively in the project, found that BIM5D technology had better application effect, and put forward suggestions on improving BIM5D technology. The BIM5D system was proposed for the first time and carried out pipeline conflict inspection to achieve accurate management of engineering cost by Ahmad Jrade ${ }^{[5]}$.

In a word, the application of BIM technology in foreign countries is relatively mature, and the application scope and depth of BIM technology in projects are gradually increasing. BIM technology has become an indispensable tool in the field of engineering construction.

\subsection{Domestic Research Status}

In terms of BIM technology research, China is relatively late than foreign countries. Hong Kong is the earliest city in China to study and apply BIM. In 2006, Hong Kong housing authority began to apply BIM technology in projects $^{[6]}$. From 2006 to 2010, China academy of architecture published a series of monographs on BIM through a series of research projects on key technologies and software of building informatization, which provided theoretical support for the application of BIM technology in engineering projects ${ }^{[7]}$. In 2014, BIM4D construction simulation in an international center project in xi an was realized by hu changming ${ }^{[8]}$ et al. based on Navisworks software. In 2014, Zhao yuehua ${ }^{[9]}$ et al. applied BIM5D technology to compile construction progress plan in the construction stage of Tianjin yongli building, which improved the level of fine management of the project.

In summary, BIM5D technology helps control the cost of a project throughout its life cycle. In the early stage of the project, BIM5D can be used for virtual construction simulation, and reasonable schedule and capital plan. In the design stage, multiple people can compile the design budget and construction drawing budget based on the same platform, so as to improve the accuracy of the estimate and budget. During the construction phase of the project, the BIM5D system can not only carry out the project pricing, measurement and settlement, but also automatically save the project change record for easy inquiry. In addition, the system can also update the project cost information in real time, control the project cost in real time, and realize the fine management of the project cost.

\section{Project overview of Gucun international foreign language school}

The project base is located in the east and north of baoan highway and west of planning road, baoshan district, Shanghai. The terrain is irregular trapezoid. The existing gas station is located in the northwest corner, opposite baoan highway is a newly built high-rise residential community, the northwest part of the base is a country trail, the northeast part is $20 \mathrm{~m}$ planned road, the road is adjacent to the river. The Shanghai gucun experimental school was located east for the river, the southeast of the base is municipal public green space.

\footnotetext{
* Corresponding author: yuanzhijiexue@126.com
} 
Gucun international foreign language school is designed and planned to be two relatively independent and related teaching areas, namely middle school department and primary school department. The project mainly includes the primary school middle school, high school teaching building, administrative office building, art building, dormitory building, canteen and sports complex building. The total construction area of the project is 55814 square meters, with a plot ratio of 0.926 . The above-ground construction area is 50,425 square meters, the underground construction area is 5,389 square meters, and the building density is $22.60 \%$.

\section{Application process}

Project information of Gucun international foreign language school was inputted in the BIM5D software. The underlying data (such as manifest and model) were associated by importing project models, materials, budget files, and so on. By dividing the flow section, the information of component quantity and bill quantity was viewed according to the flow section. In the panorama browsing option, the $3 \mathrm{~d}$ model is viewed in the dimension of time, as well as the component quantities related to the model, bill quantities, project progress status, capital curve and resource curve. It has enriched the technical means of cost control and project management.

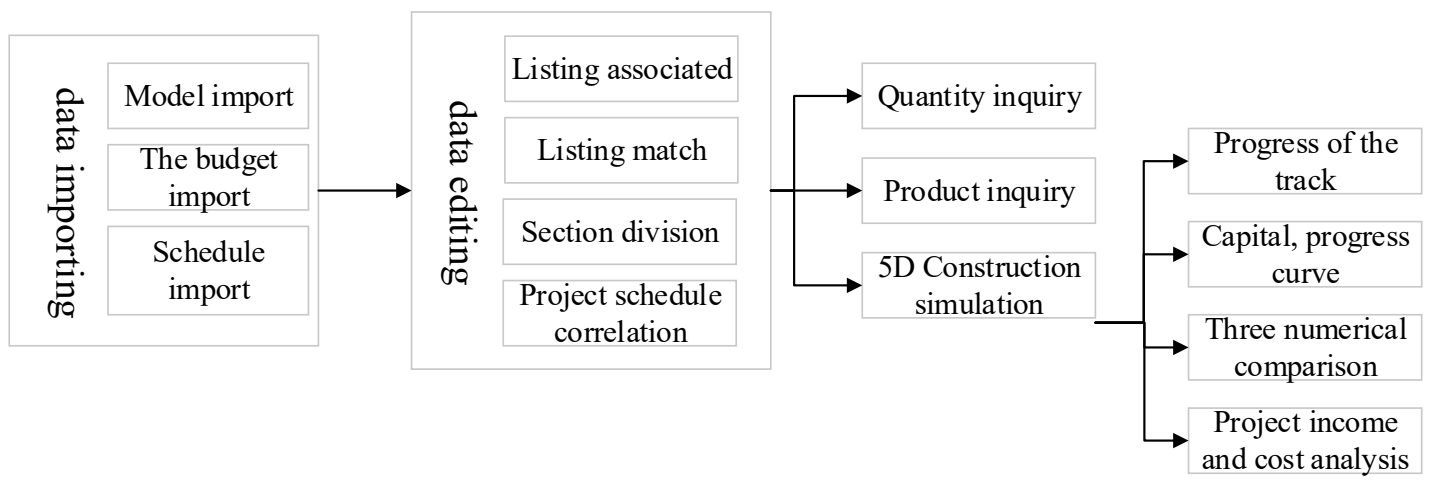

Fig. 1. BIM 5D implementation flowchart.

In this project, the BIM5D collaborative platform was applied for cost management to realize real-time cost monitoring during the project implementation. At the same time, the BIM5D collaborative platform was applied in the construction process to cooperate with the owner and the participants. Therefore, the cost control was systematic, traceable and forward-looking.

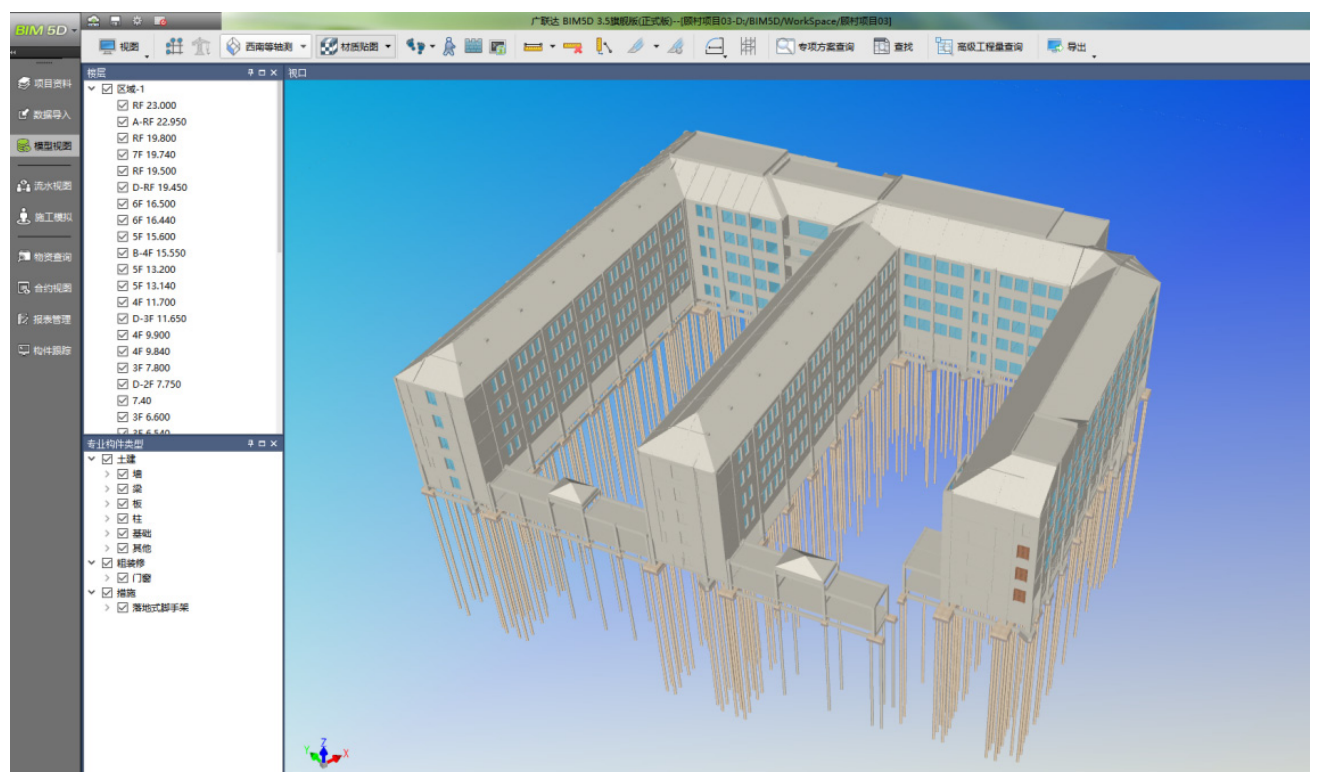

Fig. 2. Import the model. 


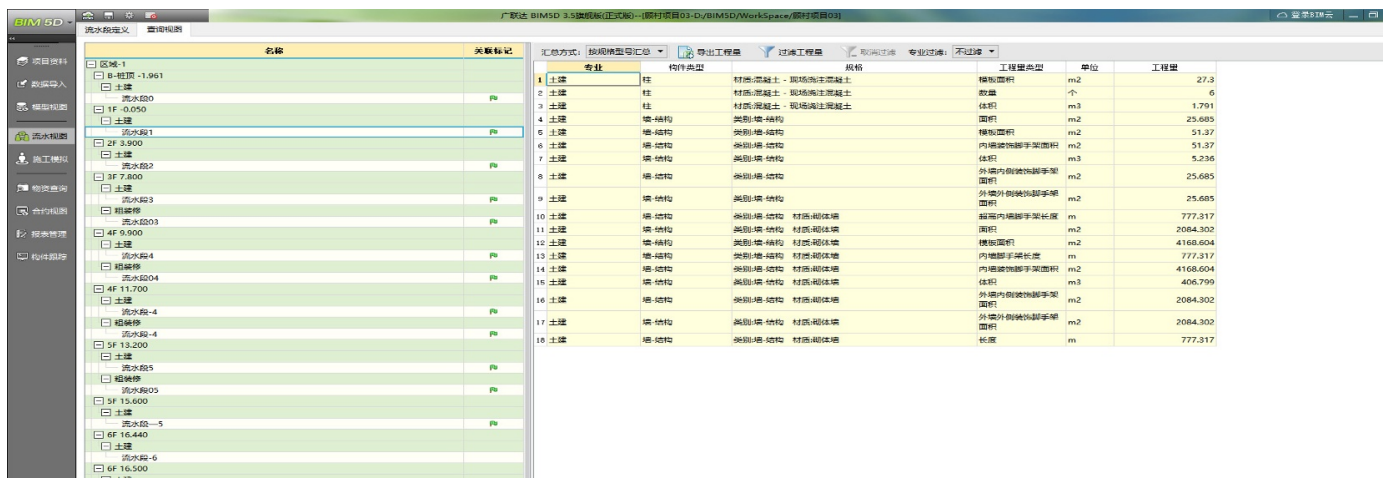

Fig. 3. Engineering flow section division.

The dynamic ledger board of BIM 5D PC dynamic cost can monitor each cost item, dynamic cost change, overspend or savings in real time. The dynamic cost of each subitem was summarized in real time by linking the contract of the project and the amount of change. Through the account waiting for occurrence, the estimated amount of each cost sub-item waiting for occurrence can be checked in real time to provide guarantee for the allocation of project funds.

\section{Conclusion}

By introducing BIM 5D technology into the project of Shanghai gucun international foreign language school, construction simulation, design scheme optimization and cost management were carried out, which not only ensured the smooth implementation of the project, but also saved the project cost.

(1) Based on BIM5D platform, the project team used the same model for engineering calculation and valuation, and the imported model was automatically calculated, which not only improved the accuracy of budget

\section{References}

1. Jiancheng Li. The pioneer of bim-professor charles eastman[J]. Journal of information Technology in Civil Engineering and Architecture, 6,114-117(2014)

2. Sun xiao. Design of $3 \mathrm{~d}$ simulation system for transition space of exhibition building based on BIM technology[J]. Science, technology and engineering, 18, 216-221(2018)

3. Tulk J, Hanff J. 4D Construction Sequence PlanningNew Process and Data Model[C]. CIB-W7824th International Conference on Information Technology in Construction, Maribor, 79-84(2007)

4. Mc Cuen T. Scheduling, estimating, and BIM: A profitable combination[J]. AACE International Transactions, 1-9 (2008)

5. Jrade A, Lessard J. An Integrated BIM System to Track the Time and Cost of Construction Projects: A preparation and budget, but also shortened the time of budget preparation and budget by $30 \%$, saving time for construction. The minimum granularity of people, materials and machines of the project was managed, to reduce the cost loopholes and control the cost deviation degree to less than $0.5 \%$.

(2) BIM 5D is used to get through the model, cost and schedule information to help optimize the construction organization and strengthen the control of the construction process. Through 5D simulation, the project team found 18 unreasonable scheduling places, and in the process of linking the list and schedule, the cross-check found that 3 lists did not match the schedule. Through this series of checks, we can ensure that there are no missing items in the progress plan, increase the reliability of the progress plan, and greatly reduce the duration extension and cost waste caused by the imperfect progress plan in the later period.

Through the use of cost information and progress information, can avoid the past cost control and progress control, can achieve dynamic management, and static as the main control of the information island is difficult to solve the crux of the actual construction cost accounting.

Case Study[J]. Journal of Construction Engineering, 3, 1-10(2015)

6. HongXin Fan, Hongling Guo, Zhigang Jin. Opportunities and Challenges of BIM Implementation: Current Practice in Hong Kong[J]. Journal of information Technology in Civil Engineering and Architecture,3, 58-65(2010)

7. Weizhuo Zhao. Study on dynamic integration mechanism of BIM technology and evaluation index system of low-carbon green building $[\mathrm{J}]$. Science, technology and engineering, 19, 196-201(2019)

8. Changming $\mathrm{Hu}$, Huanjun Xiong, Huiyuan Long. Study on joint control of construction project schedule and cost based on BIM[J]. Journal of xi 'an university of architecture and technology (natural science), 46, 474-478 (2014)

9. Yuehua Zhao, Yitao Wang. BIM5D application in tianjin yongli building project[J]. Urban residential, (8): 42-46( 2014) 